\title{
EVOLUÇÃO MICROESTRUTURAL DE UMA LIGA DE ALUMÍNIO 7474-T7351 SUBMETIDA A LAMINAÇÃO CRUZADA E RECRISTALIZADA COM DIFERENTES TEMPOS DE ENCHARQUE *
}

\author{
Saulo Brinco Diniz ${ }^{1}$ \\ Renato Batista da Cruz ${ }^{2}$ \\ Andersan dos Santos Paula ${ }^{3}$ \\ Luiz Paulo Mendonça Brandão ${ }^{4}$
}

\section{Resumo}

O alumínio e suas ligas por apresentarem uma série de vantagens, são largamente utilizados em diversas aplicações. O que mais reduz o campo de sua aplicação é sua baixa resistência mecânica, porém esta pode ser modificada através da adição de determinados elementos de liga e de processamentos termomecânicos adequados. Este trabalho teve como objetivo estudar a evolução microestrutural de uma liga de alumínio 7475-T7351 processada por laminação cruzada, e posteriormente submetida ao tratamento térmico de recozimento a $500^{\circ} \mathrm{C}$ para recristalização, com tempos de encharque de 15, 30, 60 e 120 minutos. De acordo com os resultados apresentados, pode-se observar que a completa recristalização ocorreu entre os tempos de 30 a 60 minutos de encharque no tratamento térmico.

Palavras-chave: Laminação Cruzada; recozimento para recristalização; Microscopia Óptica; Difração de Raio-X.

\section{MICROSTRUCTURAL EVOLUTION OF A 7474-T7351 ALUMINUM ALLOY SUBMITTED TO A BROADSIDING AND RECRIDALIZED WITH DIFFERENT SOAKING TIMES}

\begin{abstract}
Aluminum and its alloys have a number of advantages and are widely used in several applications. The low yield strength reduces the application field, but it can be modified by suitable alloying elements addition and thermomechanical processes. The objective of this work was study the microstructural evolution of a 7475-T7351 aluminum alloy processed by broadsiding, and annealed at $500^{\circ} \mathrm{C}$ with diferentes soaking times $(15,30,60$ and 120 minutes). According to the results, it can be observed that the complete recrystallization taken place between 30 to 60 minutes related with soaking times during the heat treatment.
\end{abstract}

Keywords: Broadsiding; Annealing; Optical Microscopy; X-Ray Diffraction

1 M.Sc., Eng. Metalurgista, Doutorando em Ciência dos Materiais (PGCM/SE-4), IME, Rio de Janeiro - RJ, Brasil; Professor DI - 1, CEFET - Angra dos Reis, Angra dos Reis, RJ, Brasil.

2 M. Sc., Eng. de Materiais, Doutorando em Ciência dos Materiais (PGCM/SE-4), IME, Rio de Janeiro, RJ, Brasil.

3 D.Sc. M.Sc., Eng. Metalurgista, Professora Adjunta (PGCM/SE-4), IME, Rio de Janeiro - RJ e orientadora credenciada do PPGEM/UFF, Volta Redonda, RJ, Brasil.

4 D.Sc., M.Sc., Eng. Metalurgista, Professor Associado (PGCM/SE-4), IME, Rio de Janeiro - RJ, Brasil. 


\section{INTRODUÇÃO}

O alumínio e suas ligas por apresentarem uma série de vantagens, são largamente utilizados em diversas aplicações, porém o que reduz o campo de sua aplicação é o seu baixo ponto de fusão $\left(660^{\circ} \mathrm{C}\right.$ para o alumínio puro) e sua relativa baixa resistência mecânica [1 - 4]. No que diz respeito a baixa resistência mecânica do alumínio, esta pode ser aumentada com a adição de determinados elementos de liga, e quando submetidas a tratamentos termomecânicos adequados [1].

No sistema de classificação das ligas de alumínio, as ligas da série 7XXX se enquadram no grupo das ligas trabalháveis, ou seja, ligas que são submetidas a processos de conformação mecânica durante sua produção. Este mesmo grupo se subdivide em ligas não tratáveis termicamente e ligas tratáveis termicamente, no qual este último grupo é composto pelas ligas que sua resistência mecânica pode ser aumentada através de tratamentos térmicos [2, 3].

O processamento termomecânico consiste na conjunção de deformação mecânica e tratamentos térmicos. Dentre os diversos métodos de conformação mecânica possíveis para aumentar a resistência mecânica do alumínio e suas ligas, a laminação cruzada tem como objetivo quebrar estruturas de grãos alongados desenvolvida na laminação a quente convencional. A operação de laminação cruzada é similar a da laminação convencional, porém a cada passe de laminação a chapa é rotacionada $90^{\circ}$ em relação a direção de laminação original da chapa.

De acordo com a temperatura em que se realiza o trabalho mecânico, no caso do alumínio e suas ligas, devido sua baixa temperatura de fusão, uma deformação mecânica realizada na temperatura ambiente, pode ser considerada como trabalho a morno, pois os fenômenos de recuperação podem se fazer presentes (de maneira mais significativa quanto menor for a temperatura de fusão da liga, e maior o incremento de temperatura dado pelo trabalho mecânico devido a ausência e/ou ineficiência da solução de lubrificação/refrigeração utilizada no processo de deformação, como por exemplo, a laminação).

Com trabalho a frio ou morno de ligas de alumínio [3, 5], tem-se uma estrutura encruada ou recuperada, e consequentemente um maior limite de resistência. Porém dependendo da aplicação em que o material se destina sua utilização não é viável devido à baixa ductilidade resultante, e desta forma é necessário realizar um tratamento térmico posterior ao trabalho mecânico para recuperar a ductilidade da liga, embora a resistência mecânica também reduza um pouco após este tratamento $[6,7]$.

O tratamento térmico de recozimento para recristalização tem como objetivo a nucleação de grãos livres de tensões, que acontecem no interior dos grãos deformados, e após o seu crescimento consumindo os grãos deformados/ recuperados, resultam em uma nova estrutura de grãos, com uma baixa densidade de discordâncias [2, 8, 9].

Para a ocorrência da nucleação da recristalização ou para que a cinética da recristalização seja aumentada, é necessário alguns fatores estruturais, tais como: quantidade mínima de encruamento, ou seja, quanto menor o encruamento inicial, maior será a temperatura para se iniciar a recristalização; pureza do material, ou seja, quanto mais puro o material menor será a temperatura de recristalização [10]; a presença de precipitados dispersos na matriz metálica, pois estes podem favorecer ou retardar o início da recristalização, de acordo com a natureza química, morfologia, distribuição, tamanho e quantidade dos mesmos [9 - 11]. 
Após o mecanismo de recristalização estar completo, ou seja, não há o aparecimento de novas regiões recristalizadas na amostra, os grãos agora livres de tensões internas, tendem a crescer, e esse crescimento de grão é favorecido pela permanência a temperaturas acima da temperatura de recristalização [10].

Este trabalho tem como objetivo, estudar a evolução microestrutural de uma liga de alumínio 7475-T7351 processada por laminação cruzada, e posteriormente submetida ao tratamento térmico de recozimento para recristalização a $500^{\circ} \mathrm{C}$, com tempos de encharque de 15, 30, 60 e 120 minutos. Para tal objetivo, foram usadas as técnicas de Microscopia Óptica (MO) e Difração de Raio-X (DRX).

\section{MATERIAL E MÉTODOS}

Para este estudo foi utilizado uma liga de alumínio 7475-T7351 (segundo a norma SAE AMS4202), na forma de chapa laminada a quente com uma espessura inicial de 12,5 mm, previamente estudado por Diniz, 2015 [12] e Diniz, 2016 [13] (denominada de amostra como recebida (CR) nestes estudos). Na Tabela 1, está presente a composição química (\% em peso) da liga 7475-T7351 obtida por espectroscopia de emissão ótica.

Tabela 1. Composição química da liga 7475-T7351 em estudo (\% em peso).

\begin{tabular}{|c|c|c|c|c|c|c|c|c|c|}
\hline \multicolumn{8}{|c|}{ Composição química da liga 7475-T7351 (\% em peso) } \\
\hline $\mathbf{A l}$ & $\mathbf{Z n}$ & $\mathbf{C u}$ & $\mathbf{M g}$ & $\mathbf{S i}$ & $\mathbf{F e}$ & $\mathbf{M n}$ & $\mathbf{C r}$ & $\mathbf{~ N i}$ & $\mathbf{T i}$ \\
\hline 89,5000 & 5,6700 & 1,7800 & 2,3800 & 0,0438 & 0,2420 & 0,0090 & 0,1970 & 0,0132 & 0,0413 \\
\hline $\mathbf{B e}$ & $\mathbf{C a}$ & $\mathbf{V}$ & $\mathbf{P b}$ & $\mathbf{S n}$ & $\mathbf{Z r}$ & $\mathbf{G a}$ & $\mathbf{C d}$ & $\mathbf{C o}$ & Outros \\
\hline 0,0004 & 0,0028 & 0,0184 & 0,0041 & 0,0057 & 0,0007 & 0,0092 & 0,0038 & 0,0032 & 0,0754 \\
\hline
\end{tabular}

O corpo de prova proveniente da condição CR $[10,11]$ foi cortado com dimensão de $60 \times 50 \times 12,5 \mathrm{~mm}$ (DL x DT x DN, respectivamente) a fim de ser laminado. Foram realizados um total de 7 passes de laminação cruzada a temperatura ambiente (em um laminador do fabricante FENN MFG. Co., modelo D-51710:1973, 133,70 mm de diâmetro dos cilindros), com uma redução aproximada de $10 \%$ por passe, até se obter uma espessura de $6,1 \mathrm{~mm}$. Na Figura 1 encontra-se apresentado esquematicamente como foi realizada a laminação cruzada.

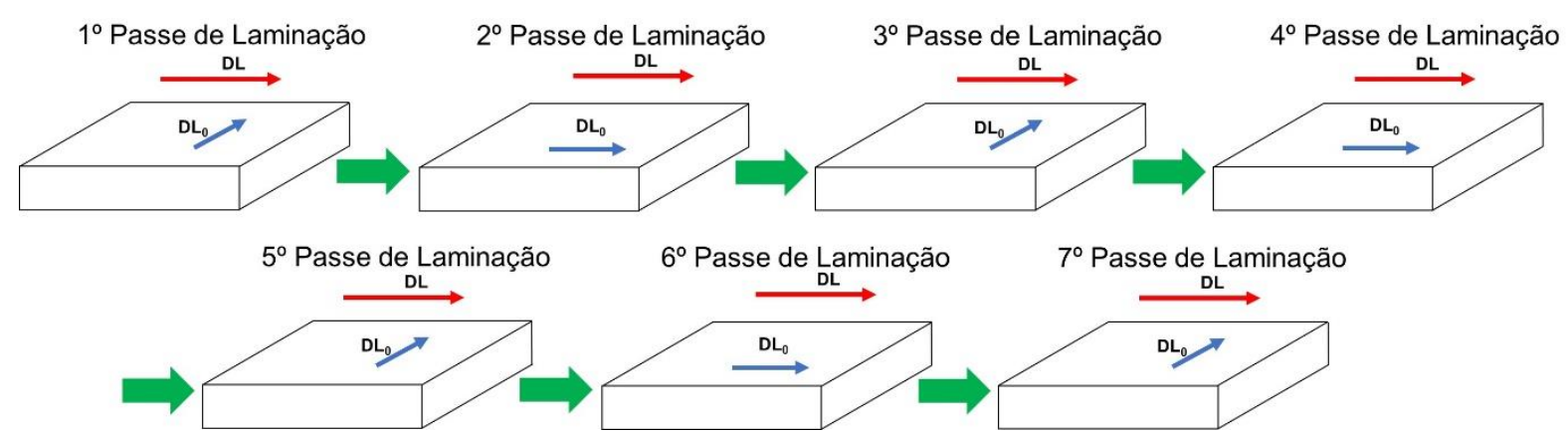

Figura 1. Esquematização da laminação cruzada. Na imagem DL representa a direção de laminação no passe e $D_{0}$ a direção de laminação original da chapa laminada a quente.

Após a laminação cruzada, a amostra foi seccionada em 5 partes, no qual uma deu origem a amostra LZ, ou seja, amostra submetida a laminação cruzada até $6,1 \mathrm{~mm}$. As outras 4 partes seccionadas foram submetidas a um tratamento térmico de recozimento para recristalização (em um forno de resistência elétrica, fabricante 
EDG, modelo 3000), a uma temperatura de $500^{\circ} \mathrm{C}$ durante $15,30,60$ e 120 minutos, originando as amostras denominadas de T15, T30, T60 e T120, respectivamente.

Para realizar a caracterização microestrutural (via MO e DRX), as amostras foram embutidas em resina epoxy, lixadas com lixas de carbeto de silício de 220 a 2500 mesh, polidas mecanicamente com abrasivos de diamantes, na forma de pasta, com granulometrias de $6 \mu \mathrm{m}, 3 \mu \mathrm{m}$ e $1 \mu \mathrm{m}$ dispersas em um pano com auxílio de lubrificante para materiais não ferrosos (lubrificante vermelho para preparação metalográfica - fabricante Arotec). O tempo de permanência em cada pasta de diamante foi de aproximadamente 15 minutos, sendo posteriormente lavadas em água corrente e álcool, e secadas com jato de ar quente.

Após o polimento mecânico as amostras foram polidas eletroliticamente com auxílio de uma solução de $30 \% \mathrm{HNO}_{3}$ e $70 \%$ de Metanol, resfriada a $-30^{\circ} \mathrm{C}$, com uma voltagem de $15 \mathrm{~V}$ durante 10 a 20 segundos. Após o polimento eletrolítico, as amostras foram atacadas com o reagente Keller $(2,5 \% \mathrm{HNO}, 1,5 \%$ de $\mathrm{HCl}, 1,0 \%$ de $\mathrm{HF}$ e $95 \%$ de $\mathrm{H}_{2} \mathrm{O}$ em volume), para que fosse evidenciado os contornos dos grãos da fase a (matriz metálica).

Para a visualização e registro da microestrutura, foi utilizado um Microscópio óptico (MO) do fabricante Olympus, modelo BX53M - acoplado a uma câmera digital (marca Olympus, modelo SC30), controlada pelo software de aquisição de imagens LCmicro. Para as amostras em estudo, foram realizadas visualizações e registro de imagens em regiões associadas a $1 / 4$ e $1 / 2$ da espessura das amostras, com ampliações de 200x (menor aumento) e 500x (maior aumento).

As análises de difração de raio-X (DRX) foram realizadas em um Difratômetro de raios- $x$ da empresa PANalytical, modelo X'Pert PRO MRD na condição de foco linha. Para esta análise foi realizada uma varredura de $40^{\circ}$ a $120^{\circ}$, com um tamanho de passo (step size) de $0,0394^{\circ}$ e tempo por passo (time per step) de $100 \mathrm{~s}$. Para a identificação dos picos difratados referente a matriz metálica, foram utilizadas as fichas JCPDS (Joint Committee on Powder Diffraction Standards) - 89-4037 (fase $\alpha$ ). Os parâmetros, largura a meia altura, área do pico e posição do pico foram obtidas através do programa X'Pert Data Viewer.

\section{RESULTADOS E DISCUSSÃO}

Na Figura 2 estão apresentadas as microestruturas obtidas por microscopia óptica da amostra CR estudada por Diniz, 2016 [13], visualizada à $1 / 4$ da espessura (a e b) e $1 / 2$ espessura (c e d) registradas com menor aumento (a e c) e maior aumento (b e d). Enquanto na Figura 3 são apresentadas as imagens obtidas por microscopia óptica, da amostra LZ com menor ampliação (a e b) e maior ampliação (c e d), visualizadas em regiões a $1 / 2$ ( a e c) e $1 / 4$ (b e d) da espessura.

De acordo com as Figuras 2 e 3, pode-se observar a presença de precipitados grosseiros, indicados por "PG", e grãos grosseiros aparentemente alongados na direção de laminação (DL). Embora no processo da laminação cruzada tenham sido realizados 4 passes na direção transversal a de laminação (DT), não foram suficientes para modificar apreciavelmente o formato dos grãos quando comparado a amostra LZ (Figura 3) com a amostra CR (Figura 2). Para melhor caracterizar o aspecto dos grãos, ou seja, se estão ou não alongados na direção de laminação, serão conduzidos como trabalhos futuros a realização de mapeamentos microtextural via Electron Backscartter Diffraction - EBSD / MEV. 


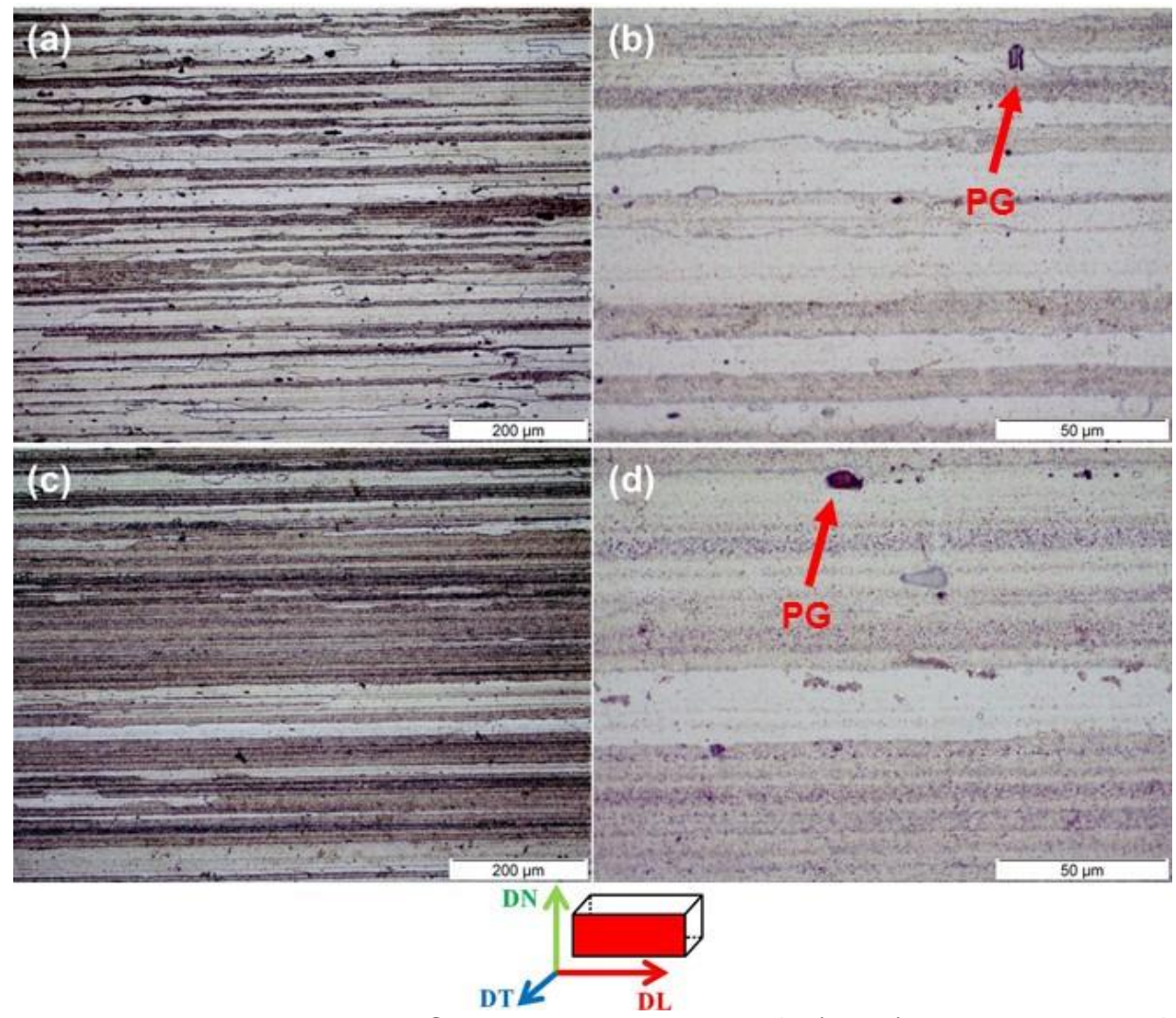

Figura 2. Microestrutura da amostra CR com menor ampliação (a e c) e maior ampliação (b e d), visualizadas em regiões a 1/4 (a e b) e 1/2 (c e d) da espessura. Direção de laminação (DL), MO, polimento mecânico, amostra atacada. Na Figura, "PG" indica os precipitados grosseiros [11] Adaptado.
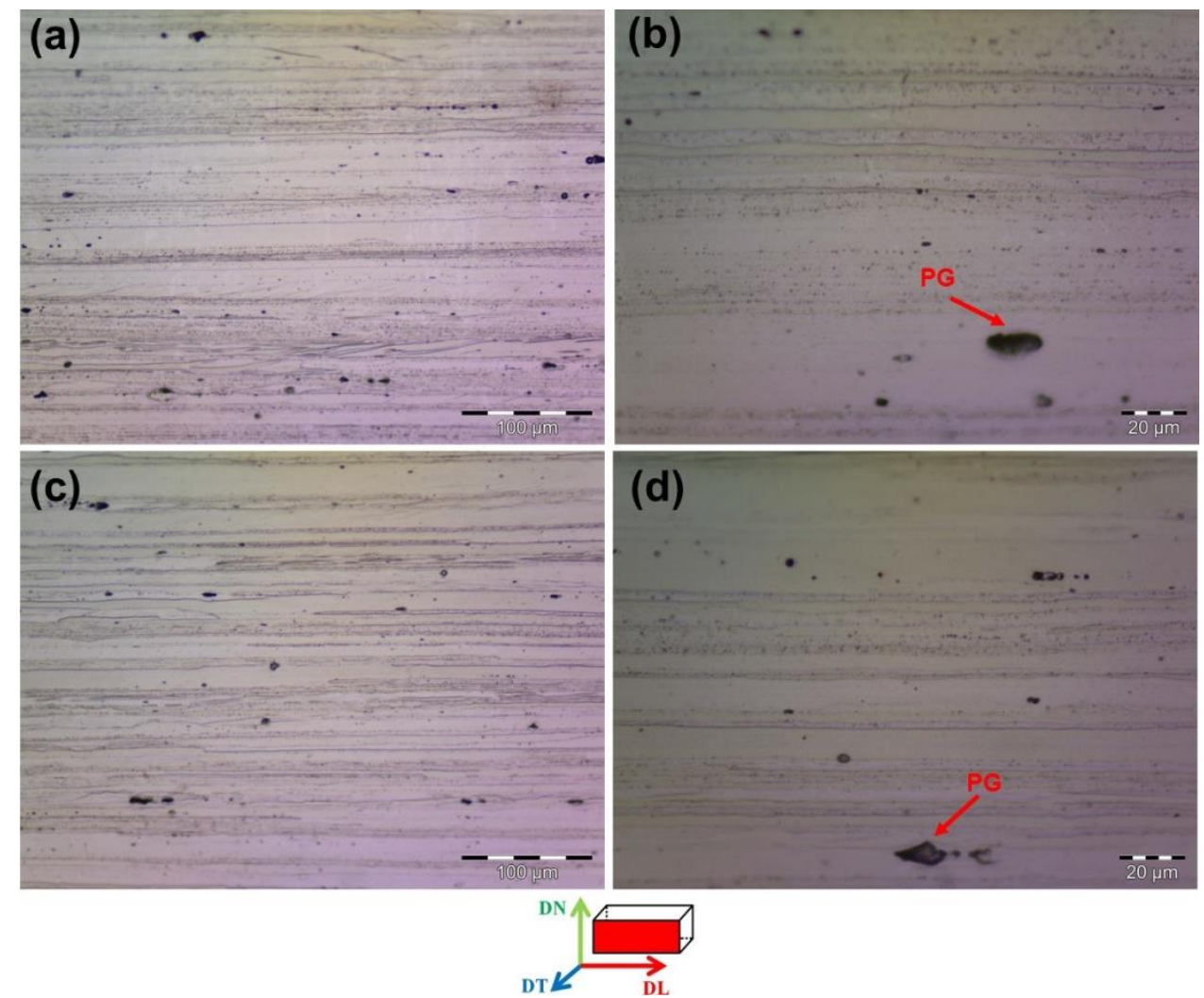

Figura 3. Microestrutura da amostra LZ6 com menor ampliação (a e c) e maior ampliação (b e d), visualizadas em regiões a 1/2 (a e b) e 1/4 (c e d) da espessura. Direção de laminação (DL), MO, polimento eletrolítico, amostra atacada. Na Figura, "PG" indica os precipitados grosseiros. 
Nas Figuras de 4 a 7 são apresentadas as imagens obtidas por microscopia óptica, das amostras recozidas (a) T15, (b) T30, (c) T60 e (d) T120, com menor ampliação (Figuras 4 e 5) e maior ampliação (Figuras 6 e 7), visualizadas em regiões a 1/4 da espessura (Figuras 4 e 5 ) e 1/2 espessura (Figuras 6 e 7 ).
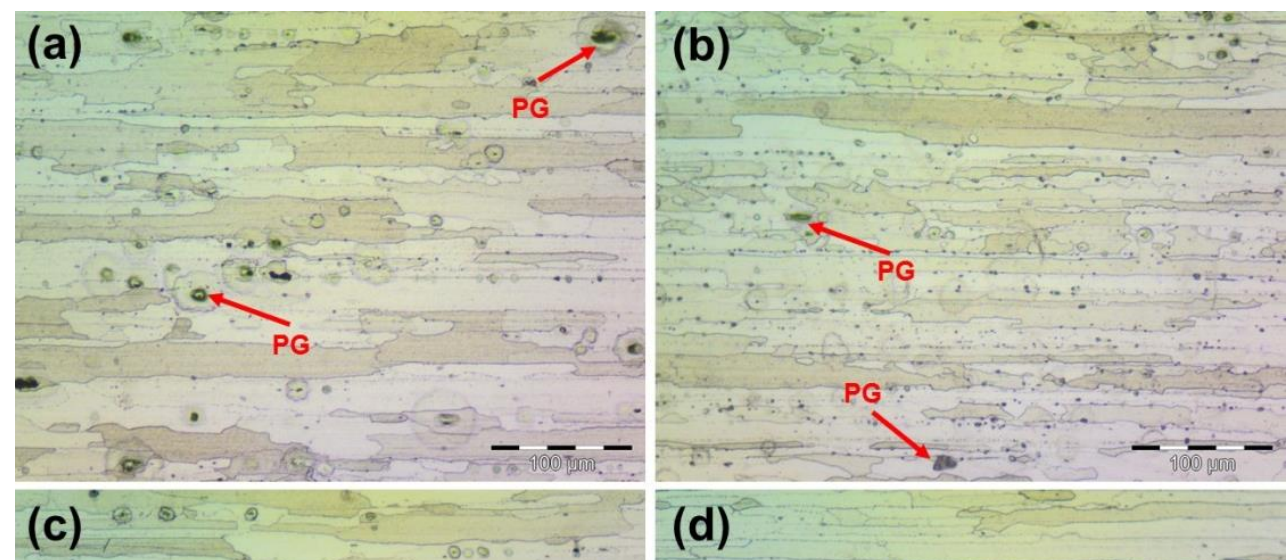

\section{(d)}
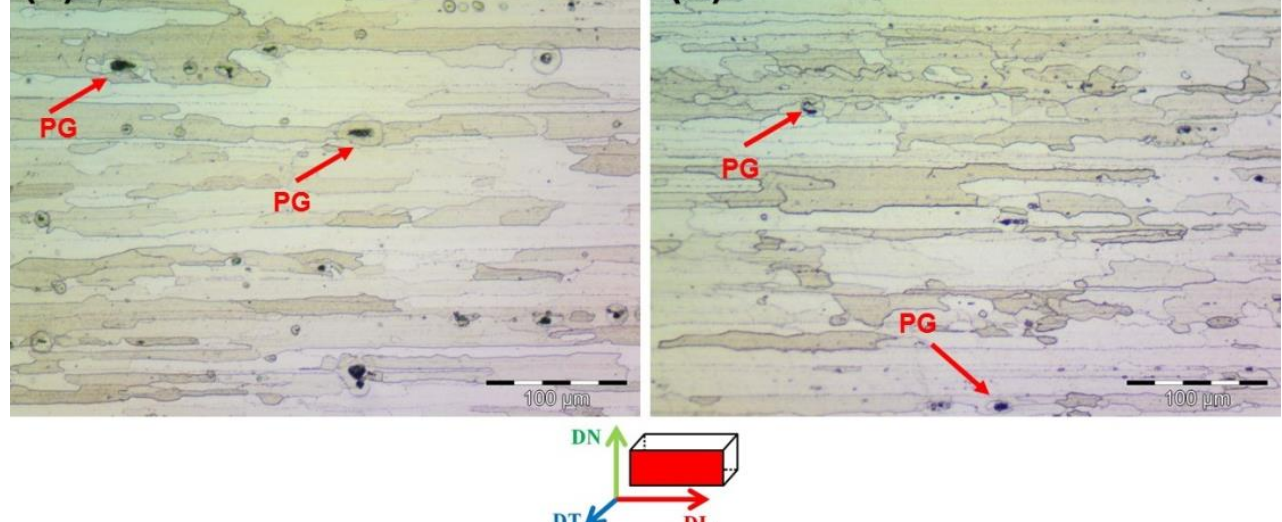

Figura 4. Microestrutura das amostras (a) T15, (b) T30, (c) T60 e (d) T120 visualizada à $1 / 2$ da espessura registradas com menor aumento. Direção de laminação (DL), MO, polimento eletrolítico, amostra atacada. Na Figura, "PG" indica os precipitados grosseiros. 

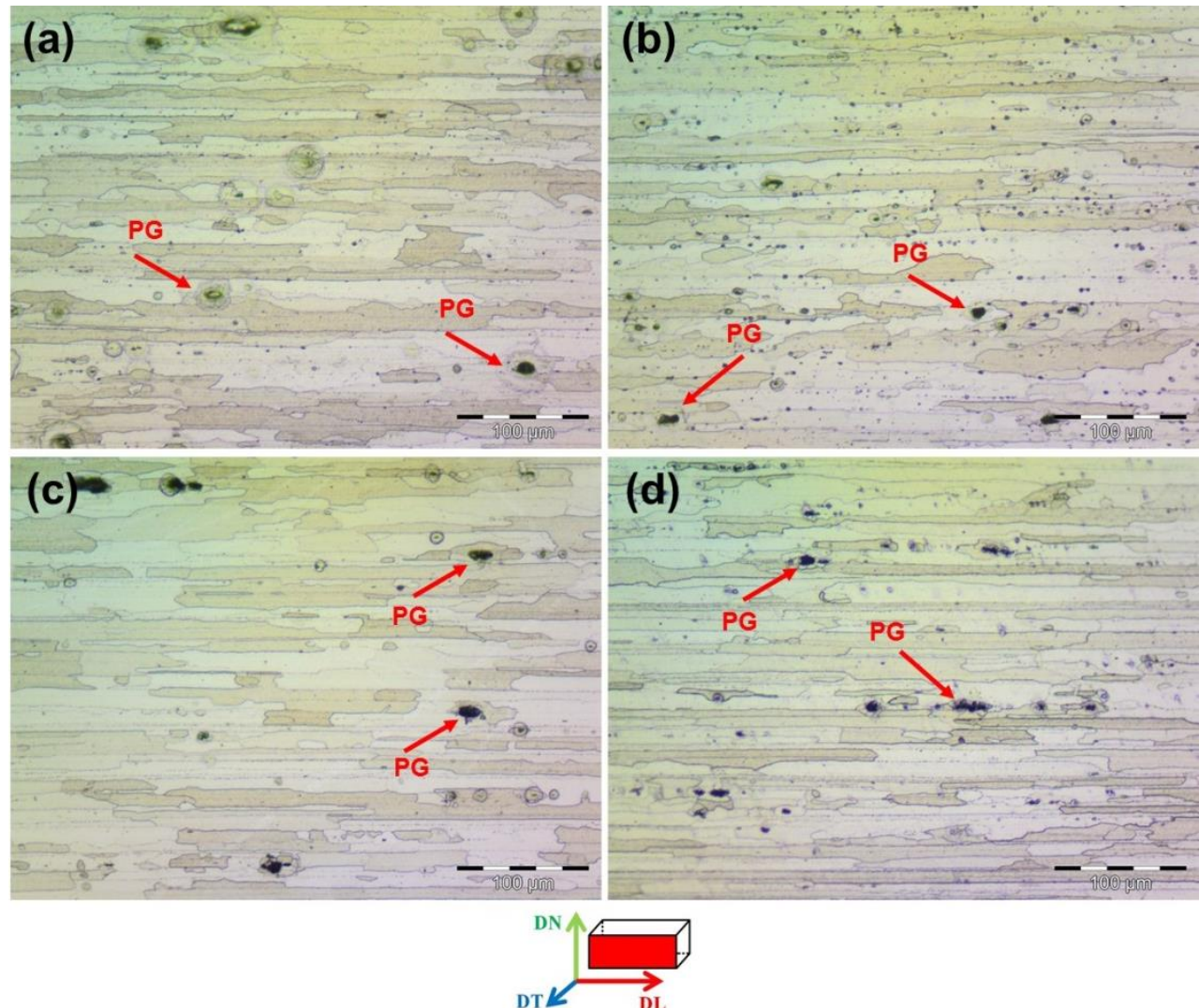

Figura 5. Microestrutura das amostras (a) T15, (b) T30, (c) T60 e (d) T120 visualizada à 1/4 da espessura registradas com menor aumento. Direção de laminação (DL), MO, polimento eletrolítico, amostra atacada. Na Figura, "PG" indica os precipitados grosseiros.
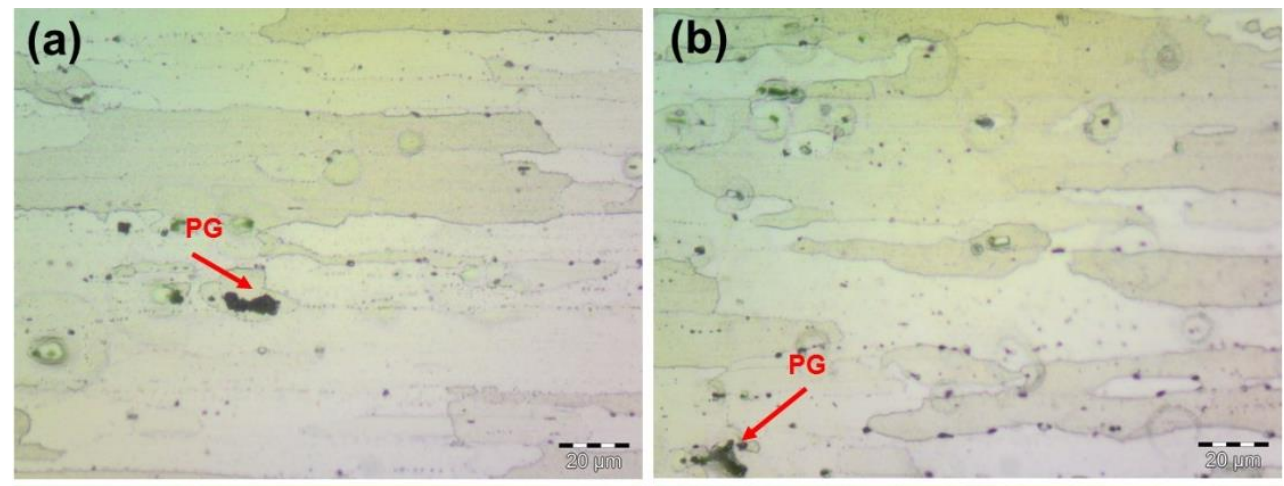

(c)

(d)
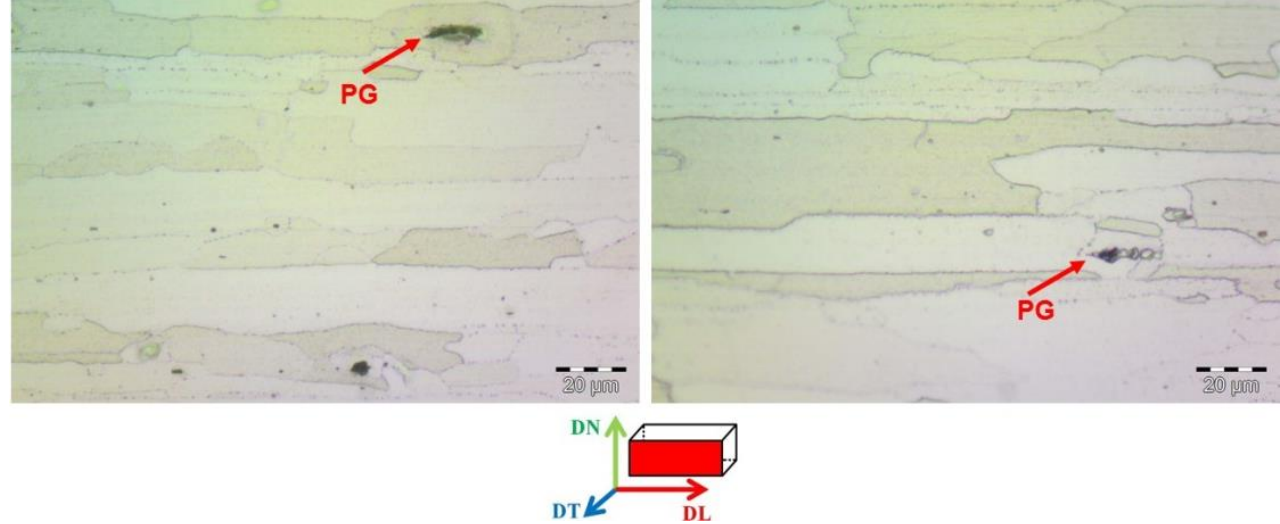

Figura 6. Microestrutura das amostras (a) T15, (b) T30, (c) T60 e (d) T120 visualizada à $1 / 2$ da espessura registradas com maior aumento. Direção de laminação (DL), MO, polimento eletrolítico, amostra atacada. Na Figura, "PG" indica os precipitados grosseiros. 

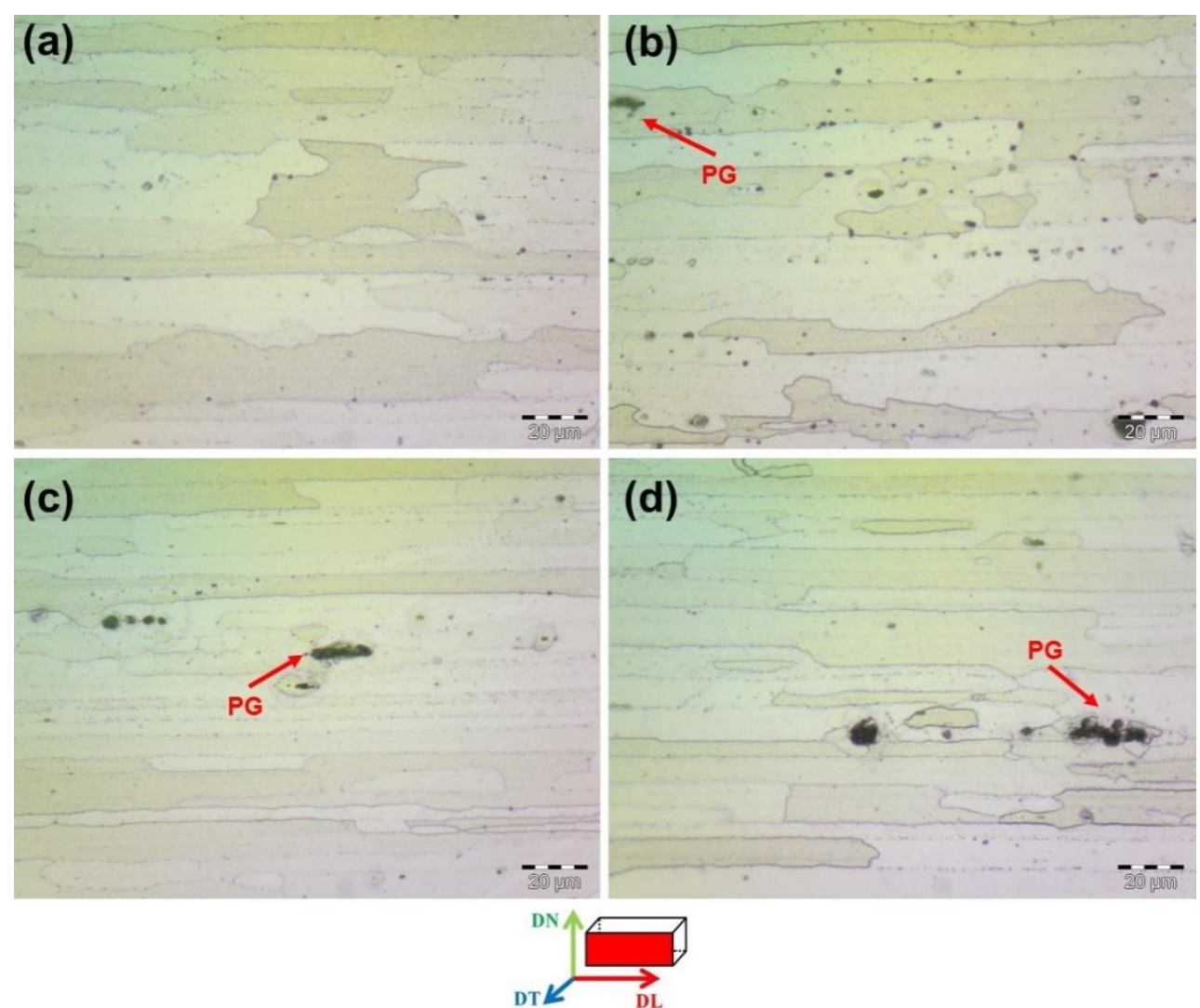

Figura 7. Microestrutura das amostras (a) T15, (b) T30, (c) T60 e (d) T120 visualizada à 1/4 da espessura registradas com maior aumento. Direção de laminação (DL), MO, polimento eletrolítico, amostra atacada. Na Figura, "PG" indica os precipitados grosseiros

Segundo as Figuras de 4 a 7 pode-se observar que com apenas 15 minutos de tratamento térmico, a amostra deformada via laminação cruzada já apresentou um estágio muito avançado de recristalização. Também pode-se observar uma sutil modificação da microestrutura entre as condições T30 e T60, no qual os grãos passaram ter subdivisões em seus interiores, fato este que indica um "possível" tempo para a total recristalização da amostra estar entre os tempos de 30 e 60 minutos de encharque para o tratamento térmico de recozimento para recristalização. Quando comparado as amostras T60 e T120, não se observa modificações apreciáveis, no que diz respeito ao formato dos grãos, e desta forma não houve crescimento dos grãos entre estas duas condições.

Na Figura 8 estão apresentados os difratogramas de Raio-X das amostras LZ, T15, T30, T60 e T120, e na Figura 9 estão apresentados gráficos que demonstram a evolução da (a) área sobre o pico e (b) largura a meia altura. 


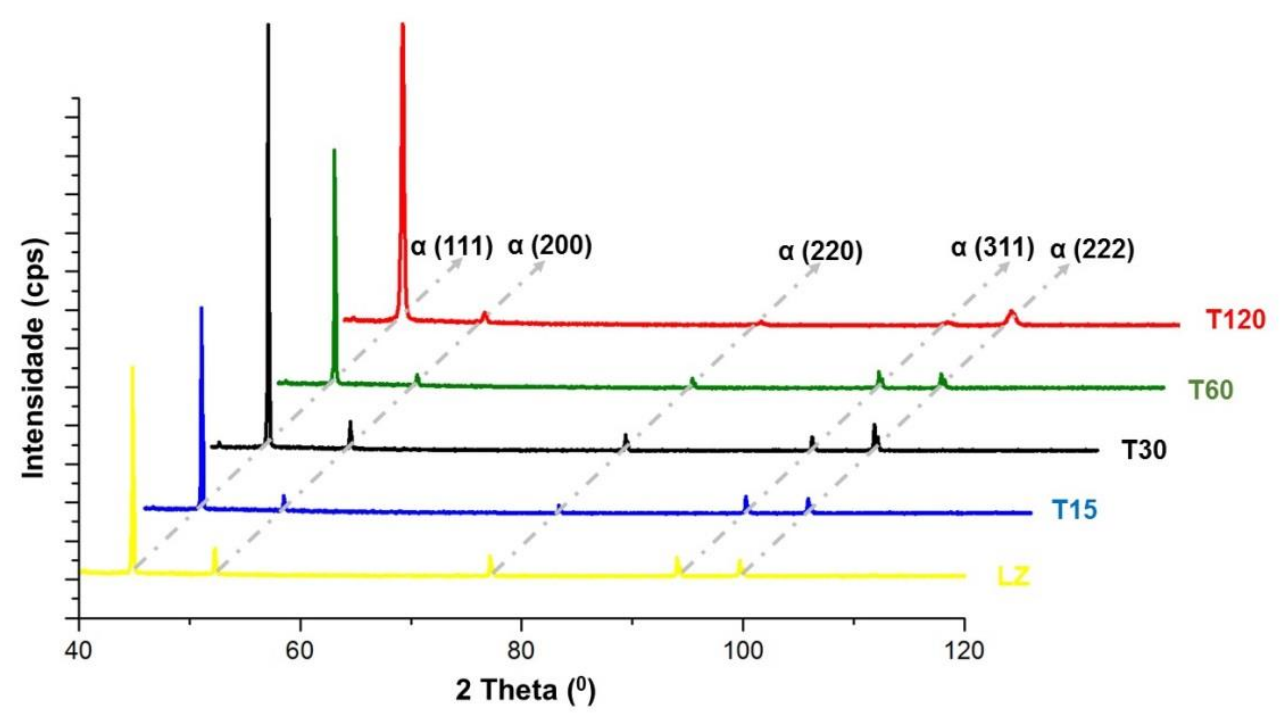

Figura 8. Difração de Raio-X das amostras LZ, T15, T30, T60 e T120.

(a) LARGURA A MEIA ALTURA

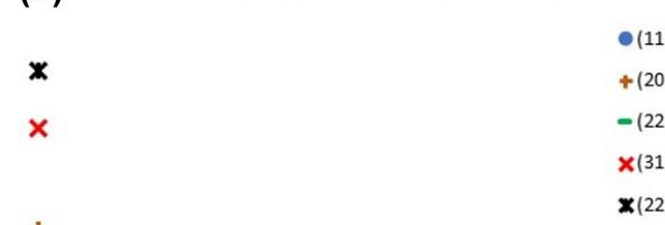

(b)

$-(111)$
$+(200)$
$-(220)$
$\times(311)$
$\mathbf{x}(222)$

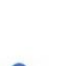

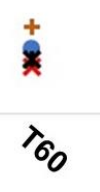
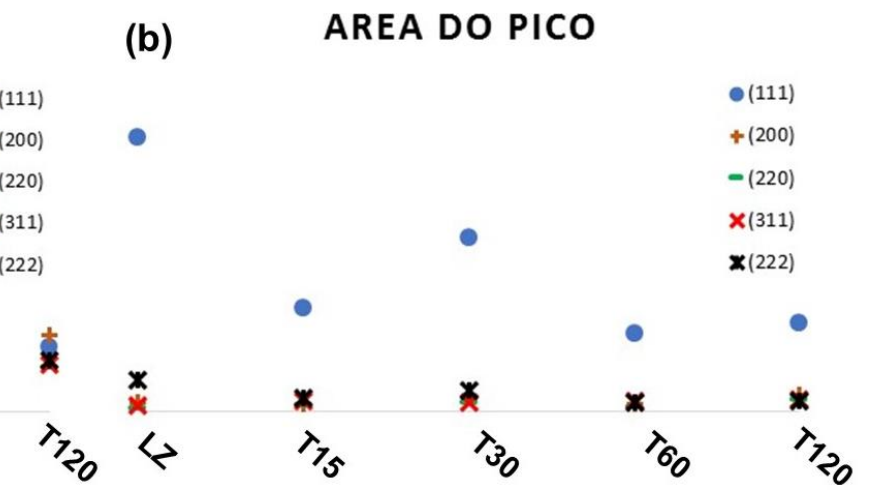

Figura 9. Evolução da (a) Largura a meia altura e (b) Área dos picos de DRX associadas a fase $\alpha$.

Com base na Figura 9, em relação à largura a meia altura, pode-se observar que este valor tem um decréscimo muito acentuado da amostra LZ para a T15, e um pequeno decréscimo da amostra T15 para T30, a partir da amostra T30, ou seja, amostras T60 e T120, não se observam modificações significativas no valor da largura a meia altura, comparadas a amostra T30. Desta forma, a diminuição da largura a meia altura dos picos de difração estão associados ao crescimento dos núcleos recristalizados, ou crescimento da fração de grãos recristalizados acompanhada pela redução da densidade de discordância. Sendo assim, pode-se inferir que o tempo da completa recristalização (e desta forma aumenta da fração volumétrica dos grãos recristalizados, devido a nucleação dos mesmos em um grão encruado) está entre os tempos de 30 a 60 minutos, ou seja, amostras T30 e T60, respectivamente.

No que diz respeito a área sob o pico, pode-se observar que para o plano (111) houve um decréscimo da amostra LZ para T15 e T30 para T60, e um aumento na área do pico das amostras T15 para T30 e T60 para T120. Já para os outros picos (200), (220), (311) e (222), não houve uma variação tão significativa. A área do pico pode ser atribuído ao possível crescimento de grão e / ou modificação da textura cristalográfica do material, porém para o pico (111) este comportamento de crescimento e refinamento de grão não pode ser possível quando se comparado às amostras em estudo, devido ao processamento termomecânico que as mesmas foram submetidas (amostra deformada submetida a diferentes tempos de encharque 
no tratamento térmico de recozimento para recristalização), sendo assim possivelmente este comportamento descrevendo a evolução da textura do material ao longo do tratamento térmico.

Desta forma, conforme apresentado nos dados acima, pode-se observar que houve a completa recristalização da amostra LZ possivelmente em um tempo de tratamento térmico de recozimento parar recristalização entre os tempos de 30 e 60 minutos (amostras T30 e T60, respectivamente) e para tempos posteriores a 60 minutos de tratamento térmico (amostra T120) não foi observado um crescimento de grão. Para se ter uma melhor descrição da evolução da recristalização com o aumento no tempo de encharque do tratamento térmico de recozimento para recristalização, serão conduzidos como trabalhos futuros a realização de mapeamentos microtextural via Electron Backscartter Diffraction - EBSD / MEV.

\section{CONCLUSÃO}

De acordo com os resultados apresentados, pode-se concluir que:

- Com a laminação cruzada da amostra CR não foram evidenciadas grandes modificações no aspecto da microestrutura quando comparada com à amostra $L Z$, ou seja, ambas as condições apresentaram aparentemente grãos grosseiros e alongados na direção de laminação original, porém são necessárias análises mais profundas, como por exemplo, mapeamentos microtexturais via Electron Backscartter Diffraction - EBSD / MEV, para se confirmar esta incerteza;

- Há indícios que a completa recristalização a 500C ocorre em um tempo de permanência dentro do forno entre 30 a 60 minutos;

- Não há crescimento de grão significativo quando comparadas as amostras T60 e T120.

\section{Agradecimentos}

Os autores agradecem a CAPES pelo auxílio financeiro via bolsa de estudos de mestrando (Diniz SB, da Cruz RB) e de doutorando (Diniz SB, da Cruz RB).

\section{REFERÊNCIAS}

1 ASM Handook. Properties and Selection: Nonferrous alloys and specialpurpose materials. Almere: ASM International; 1990.

2 Lima EPR. Estudo da cinética de recristalização da liga de alumínio AA 8011 na condição H18 [dissertação de mestrado]. Recife: Universidade Federal de Pernambuco; 2002.

3 ABAL. Fundamentos e aplicações do alumínio, associação brasileira do alumínio (ABAL), São Paulo, 2004.

4 Minatel R. Um Estudo comparativo sobre a recristalização de chapas de alumínio AA1200 e AA3003 obtidas por lingotamento contínuo (twin rollcaster) e por fundição de placas (direct chill) [dissertação de mestrado]. São Paulo: Universidade de São Paulo; 2009.

5 Oliveira JCPT. Estudo da microestrutura e da textura durante a laminação a frio e a recristalização de alumínio com diferentes níveis de pureza [tese de doutorado]. São Paulo: Universidade de São Paulo; 2009.

6 Bresciani Filho E, Zavaglia CAC, Button ST, Gomes E, Nery FAC. Conformação plástica dos metais. São Paulo: Editora da Unicamp; 1991. 
$7 \quad$ ASM Handook. Heat treating. Almere: ASM International; 1991.

8 Slámová M, Ocenásek V, Voort GV. Polarized light microscopy: utilization in the investigation of the recrystallization of aluminum alloys. Materials Characterization. 2004; 52, 165-177.

9 Humphreys FJ, Hatherly M. Recrystallization and relates annealing phenomena. Oxford: Pergamon; 2004.

10 Padilha AF, Siciliano JR F. Encruamento, recristalização, crescimento de grão e textura. São Paulo: ABM Livros; 2005.

11 Nieh TG, Wadsworth J, Shelby OD. Superplasticity in metals and ceramics. New York: Cambridge University Press; 2005.

12 Diniz SB, Paula AS, Brandão LPM. A utilização da nanoindentação instrumentada para caracterização de materiais metálicos. In: Associação Brasileira de Metalurgia, Materiais e Mineração. Anais do 70 Congresso Anual da ABM; 2015; Rio de Janeiro, Brasil. São Paulo: ABM; 2015. p. 1-10.

13 Diniz SB, Paula AS, Brandão LPM. Tratamento térmico de ressolubilização em uma liga de alumínio 7475-T7351. In: Associação Brasileira de Metalurgia, Materiais e Mineração. Anais do 71ํㅡㄹ Congresso Anual da ABM; 2016; Rio de Janeiro, Brasil. São Paulo: ABM; 2016. p. 1-9. 